\title{
Material Transfer by Friction Stir Processing
}

\author{
Alexander A. Eliseev, Tatiana A. Kalashnikova, Andrey V. Filippov, \\ and Evgeny A. Kolubaev
}

\begin{abstract}
Mechanical surface hardening processes have long been of interest to science and technology. Today, surface modification technologies have reached a new level. One of them is friction stir processing that refines the grain structure of the material to a submicrocrystalline state. Previously, the severe plastic deformation occurring during processing was mainly described from the standpoint of temperature and deformation, because the process is primarily thermomechanical. Modeling of friction stir welding and processing predicted well the heat generation in a quasiliquid medium. However, the friction stir process takes place in the solid phase, and therefore the mass transfer issues remained unresolved. The present work develops the concept of adhesive-cohesive mass transfer during which the rotating tool entrains the material due to adhesion, builds up a transfer layer due to cohesion, and then leaves it behind. Thus, the transfer layer thickness is a clear criterion for the mass transfer effectiveness. Here we investigate the effect of the load on the transfer layer and analyze it from the viewpoint of the friction coefficient and heat generation. It is shown that the transfer layer thickness increases with increasing load, reaches a maximum, and then decreases. In so doing, the average moment on the tool and the temperature constantly grow, while the friction coefficient decreases. This means that the mass transfer cannot be fully described in terms of temperature and strain. The given load dependence of the transfer layer thickness is explained by an increase in the cohesion forces with increasing load, and then by a decrease in cohesion due to material overheating. The maximum transfer layer thickness is equal to the feed to rotation rate ratio and is observed at the axial load that causes a stress close to the yield point of the material. Additional plasticization of the material resulting from the acoustoplastic effect induced by ultrasonic treatment slightly reduces the transfer layer thickness, but has almost no effect on the moment, friction coefficient, and temperature. The surface roughness of the processed material is found to have a similar load dependence.
\end{abstract}

\footnotetext{
A. A. Eliseev · T. A. Kalashnikova - A. V. Filippov · E. A. Kolubaev ( $\varangle$ )

Institute of Strength Physics and Materials Science SB RAS, 634055 Tomsk, Russia

e-mail: eak@ispms.tsc.ru
} 
Keywords Friction stir welding • Ultrasound • Aluminum alloy • Transfer layer • Roughness $\cdot$ Friction coefficient

\section{Introduction}

Friction stir welding is a solid-state process of permanent joining, which is based on mass transfer. A nonconsumable tool, rotating during welding, heats the two pieces of a material to a plastic state $\left(\approx 0.8 \cdot \mathrm{T}_{\mathrm{m}}\right)$ due to friction force and mixes them as it moves along the joint line (Fig. 1). Being a nonmelting process, friction stir welding allows joining unweldable and dissimilar materials. Weld material moves in a complex way, undergoing not only circular but also upward and downward flow. In this case, the material can be taken as a quasi-viscous fluid, while still remaining a solid phase. Insufficient or excessive heat generation causes macrodefects to form in the seam, such as voids, wormholes, lack, etc. About $80 \%$ of heat is produced due to friction of the tool shoulders against the workpiece surface [1], and mass transfer in the bulk material is mainly implemented by the tool pin. The combination of elevated temperatures and severe plastic deformation during welding induces a series of processes at various stages: recovery, annealing, static and dynamic recrystallization, etc. [2].

These processes can significantly alter a structure and properties of the material. For example, the grain structure of rolled 2024 aluminum alloy becomes equiaxial and refines by an order of magnitude (Fig. 2). Restructuring occurs at all hierarchical levels of the material: grains, subgrains, intermetallic compounds, coherent and semi-coherent particles of secondary phases, and lattice curvature. This feature makes friction stir welding applicable to surface modification. In particular, friction stir processing is capable of hardening the surface due to plastic deformation, forming composite materials by mixing particles of dissimilar materials, removing surface defects, for example, pores in products of powder additive manufacturing, etc., which offers promise for many industries. However, this comparatively recent technology (developed in 1991 at the Welding Institute of the United Kingdom) has its limitations and is still not clearly understood. In particular, deformation and heat are combined in a complex way during welding, which makes it difficult to predict

Fig. 1 Scheme of friction stir welding process

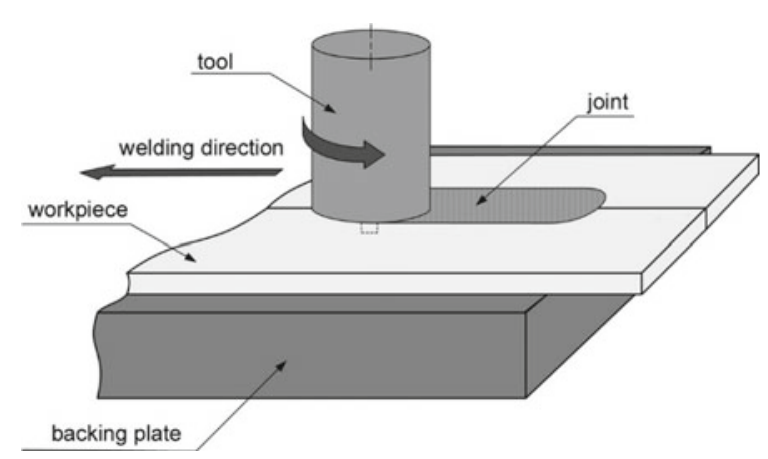



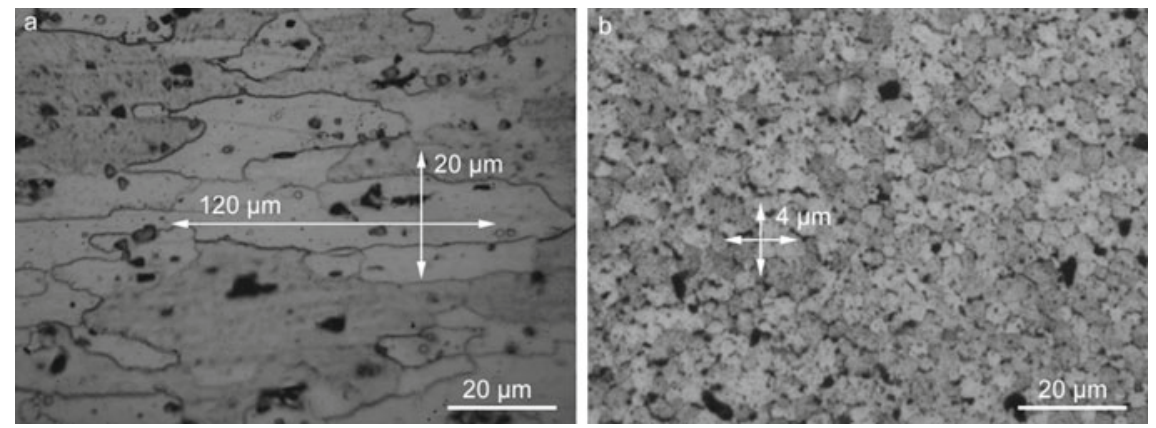

Fig. 2 Metallographic images of initial rolled sheets AA2024 (a) and after friction stir welding (b) with grain size

their effect on structure and properties. It is known from general materials science that heating coarsens grains of a solid solution and particles of secondary phases (an example is thermally hardened aluminum alloys), while deformation, due to dynamic recrystallization and strain-induced dissolution of phases, leads to grain refinement and dissolution of intermetallides in the solid solution. The influence of welding process parameters on heat generation and deformation is however nonlinear. Moreover, deformation and heat generation prove to be interrelated processes. A part of deformation energy goes into moving material macrovolumes, and a part is expended in increasing internal energy, i.e. temperature, due to internal friction. Heating, in its turn, changes viscosity of the material. Changed viscosity affects strength of the material and conditions of adhesion to the tool, i.e. deformation. To ensure the necessary temperature and deformation in practice, an optimal welding/processing mode is chosen using methods of parameter optimization, fuzzy logic, and neural networks. However, advances in the production of materials and compounds do not help to elucidate fundamental processes of friction and deformation. This work is aimed at summarizing the scientific results in this field and synthesizing them with the original experimental data.

\section{Influence of Process Parameters}

The main friction stir process parameters are tool rotation rate, tool feed rate, and axial load. Without adaptive adjustment during the process, the first two parameters are kept constant. As for load, the "soft" and "hard" modes are distinguished. The soft mode is characterized by constant axial load acting on the tool during its plunging and further processing/welding. In the hard mode, the tool plunge rate is set, and further processing occurs without significant axial load. The soft mode takes account of natural flow of the material around the tool. In the hard mode, the load varies greatly, making the process unstable as heat generation and deformation change at each 
process stage. However, the hard mode is more convenient in mass production and therefore the most common. From considerations of intensity of the impact on a material and quality of products, processing under constant axial load is favored. It also provides another way to control the process. As tool pressure, the load enters one of the classical equations of heat generation due to friction stir welding [3]:

$$
Q_{S}=\frac{4}{3} \pi^{2} \mu P \omega R_{S}^{3}
$$

where $Q_{S}$ is the friction heat generated by the tool shoulders, $\mu$ is the friction coefficient, $P$ is the pressure under the shoulders, $\omega$ is the tool rotation rate, and $R_{S}$ is the tool shoulder radius.

This equation can be conveniently used at the specified constant friction coefficient, which is often the case. However, the friction coefficient is impossible to directly measure during processing; tribological model experiments also fail to provide accurate values as the coefficient depends on the quality of surfaces, materials, rotation rate, and temperature. Thus, the friction coefficient will change not only at different process parameters but also during welding and even along the tool pin height. The coefficient can be determined analytically and verified indirectly. In one of the first equations proposed in [4], the friction coefficient for the shoulder was expressed via the moment:

$$
\mu=\frac{3 M}{2 F_{z} R_{S}}
$$

where $M$ is the measured moment, and $F_{z}$ is the axial force.

The calculated friction coefficients for aluminum alloys 5182 and F-357 are very much different at the same moment (0.35-0.55 and 0.6-1.3, respectively), which is explained by different axial load. The applied load, in turn, depends on the material properties. Kumar et al. [5] used the same approach to determine the friction coefficient but with moment in place of tangential force. He found that a higher load, under parameters being equal, increases the friction coefficient (in the range 500-1500 N and 200-1400 rev/min for alloy AA7020-T6). The friction coefficient rises to 1.4 at the maximum load and rotation rate. The measured temperature correlates with the friction coefficient and amounts to $450{ }^{\circ} \mathrm{C}$ at the maximum parameters. Thus, the temperature and friction coefficient exhibit synergy. Based on this, modeling of welding/processing should take account of the temperature dependence of the friction coefficient.

The last successful attempt was described in [6]:

$$
\mu=\frac{\tau_{0}-\tau_{1}}{\left(1-\frac{\tau_{1}-\tau_{0} \sin \alpha}{(1-\sin \alpha) \tau_{y}}\right) P_{0}(1-\sin \alpha)}
$$

where $\tau_{0}$ are the shear stresses under the pin and shoulders, $\tau_{1}$ are the shear stresses on the lateral surface of the pin, $P_{0}$ is the axial contact pressure, $\alpha$ is the tool pin 
cone angle, $\tau_{y}$ are the shear stresses determined using the von Mises yield criterion and Johnson-Cook material model with regard to temperature and strain rate. The experimentally determined and modeled welding temperatures in various modes differed by no more than $3 \%$, which confirms the adequacy of the approach.

Thus, a variation in load affects heat generation, and the related temperature variation can change the friction coefficient. These processes can influence the material adhesion to the tool and cohesion in the material. According to the adhesion-cohesion mechanism of friction stir processing, changes in mass transfer are possible, which, however, have been still disregarded. Analytical evaluation of strain is usually implemented via geometry, feed and rotation rates of the tool. For example, the classical equation of strain due to friction stir welding is [7]

$$
\varepsilon=\ln \left(\frac{l}{A P R}\right)+\left|\ln \left(\frac{A P R}{l}\right)\right|
$$

where $A P R$ is advance per revolution, and $l$ is the maximum deformed length. In fact, by $A P R$ is meant a material volume deformed per tool revolution without consideration for its adhesive transfer. This evaluation method may be adequate if the tool does not slip in the material, i.e., at optimal adhesion. However, a deformed volume does not conform to $A P R$ in every instance and in full measure. For a better understanding of deformation during friction stir processing, it is necessary to study the features of mass transfer.

\section{Adhesion-Cohesion Concept of Mass Transfer}

Mass transfer is characterized by the thickness of a transfer layer. The transfer layer is used to mean a certain material volume that sticks to the tool surface due to adhesion forces and is transferred in the rotation direction. This layer, when moving, grows in mass by capturing the surrounding material due to cohesion forces. When the critical mass is reached, the transfer layer breaks away from the tool on the trailing edge where the driving shear force of the tool and shear stresses due to the surrounding material are differently directed. A continuous material is thus formed layer by layer behind the tool. In some materials, for example, aluminum alloys, the thickness of this layer can be precisely determined at the front surface where the tool passes and in an etched longitudinal section within the material (Fig. 3).

In most works (for example in [8]), the transfer layer thickness $h$ is expressed as the ratio of the parameters:

$$
h=\frac{V}{\omega}
$$

where $V$ is the feed rate. Similar results are derived when introducing a marking material into the joint between the workpieces or placing it at the front surface. In 

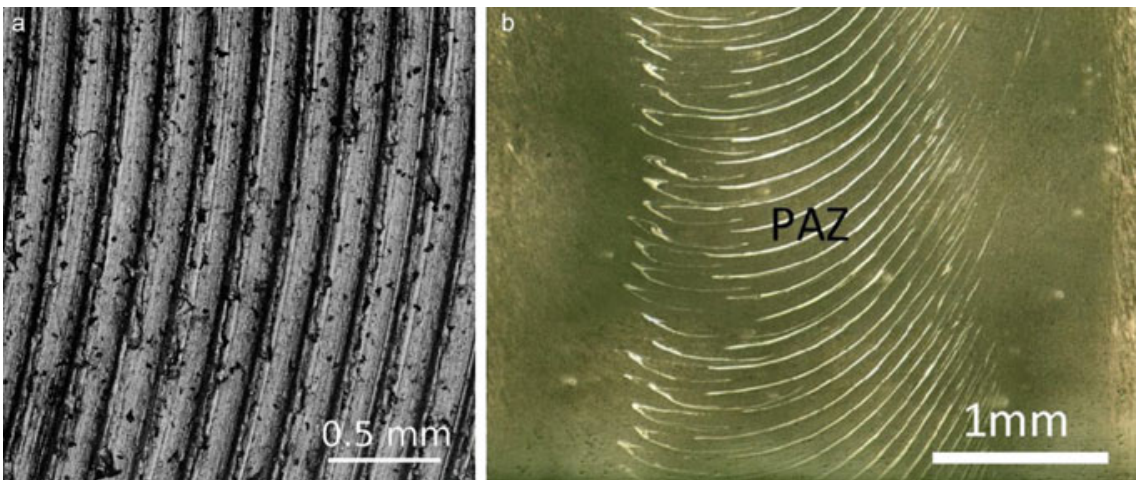

Fig. 3 Transfer layers on the front surface (a) and on the planar cross section in [9] (b)

this case, planar and cross sections demonstrate fragmented lamellae of the marking material at the boundaries of transfer layers [9]. Appearance of the marking material at the transfer layer boundary is evidence for the process of separation of materials with different densities, i.e. the vortical motion of a quasi-liquid material during processing.

However, the transfer layer thickness can be inconsistent with the given formula or can depend on conditions being neglected in it. For example, in [10] we revealed a variation in the transfer layer thickness when friction stir welding of 2024 aluminum alloy is accompanied by ultrasonic vibrations transmitted into the workpiece. Ultrasonic vibrations activate the acoustoplastic effect, which, in this context, means deformation intensification, making changes in adhesive-cohesive transfer possible. In [11] described an adhesion model based on the number of valence electrons and interatomic distance. Severe plastic deformation causes curvature of the crystal lattice and motion of electron gas [12]. Thus, any slight variation in temperature or load during friction stir welding can change transfer conditions. Under significant loads, strains, and strain rates, the material behaves differently. An example is cyclic phase transformation with intermediate amorphization [13], which can also affect the adhesive-cohesive transfer.

In [14] we performed a model experiment on ball-on-disk dry sliding friction at the ambient temperatures 25,100 , and $200{ }^{\circ} \mathrm{C}$. Test specimens were balls made of bearing structural 100Cr6 steel $6 \mathrm{~mm}$ in diameter and a disk made of 5056 aluminum alloy $50 \mathrm{~mm}$ in diameter. The test conditions were the load acting on the ball $1 \mathrm{~N}$, sliding velocity $0.5 \mathrm{~m} / \mathrm{min}$, and sliding distance $4 \mathrm{~km}$. The friction force was observed to oscillate and vary in testing, which can be explained by the sticking and detaching cycles of the aluminum alloy as well as by local temperature increase. The higher was the test temperature, the greater was the friction coefficient variation. The friction coefficient decreased with sliding distance but increased on average with temperature (Fig. 4a).

The analysis of the wear surface of the steel balls showed the presence of a transfer layer in the form of separate islands of transferred material. In the longitudinal 

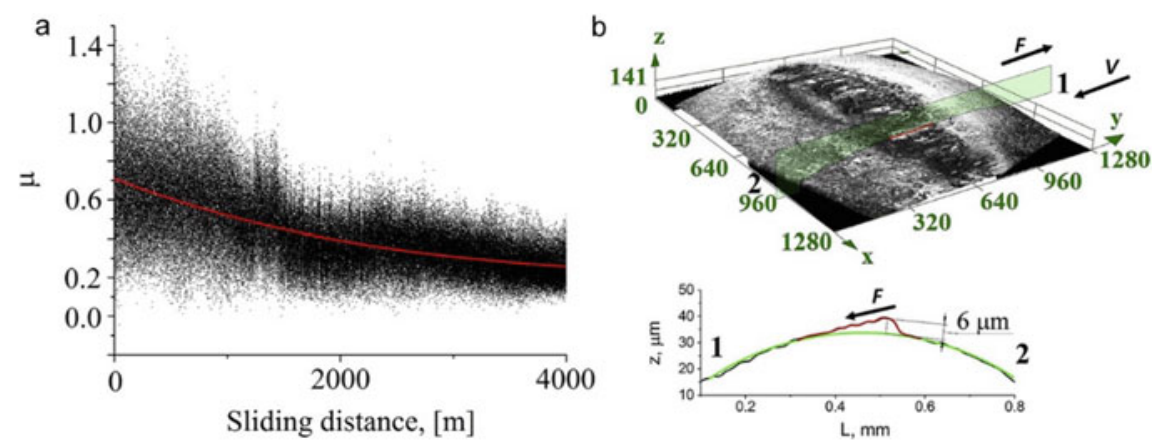

Fig. 4 Friction coefficient at sliding (a), and the wear scar and transfer layer on the ball bearing steel surface after sliding (b) [14]

section the islands had a wedge-shaped form, and the layer thickness was maximum at the trailing edge of the ball relative to its central axis (Fig. 4b). The transfer layer parameters were average thickness, maximum thickness, width of islands, and contact spot area. All the layer parameters increased with temperature. The most intensive transfer was on the specimen tested at $200{ }^{\circ} \mathrm{C}$. The analysis of friction tracks shows the presence of aluminum particles transferred back and smoothed above the tribological layer. The mechanically stirred tribological layer had marks of plastic deformation in the form of sliding bands and curved grain boundaries. In so doing, the layer depth increased at higher test temperature. The presence of such a layer is typical for sliding friction, but bulges smoothed above it testify reverse transfer of the material from ball to disc. The analysis of the transfer layer thickness shows that the reverse process is most intensive at the ambient temperature $100{ }^{\circ} \mathrm{C}$. At the temperature $25^{\circ} \mathrm{C}$, normal wearing with weak transfer of aluminum to the steel ball prevails, and at the temperature $200{ }^{\circ} \mathrm{C}$ direct transfer to the ball prevails. Reverse transfer is weakly pronounced in this case as in overheating the transfer layer serves as a lubricant and is uniformly distributed over the disc. In fact, these three modes take place between the tool and workpiece during friction stir processing, but underheating or overheating (with the adhesion-cohesion balance being broken) causes defects to form.

Technically, detachment of the transfer layer form the tool is as a rule incomplete during welding and should be so. After welding, there is always a certain layer of the workpiece material adherent to the tool. This occurs in welding of any materials: aluminum, titanium, copper alloys, etc. Therefore, the tool used to weld one alloy must not treat another material, unless required by the experimental condition. Moreover, a tool first time in use never demonstrates optimal processing results, even at the specified process parameters, until it is covered by a layer of the material being processed. This can be evidenced by the friction coefficient variation depending on the distance passed by the steel ball. Thus, a natural surface is formed on the tool, which provides an effective transfer of the material during friction stir welding. This layer is adherent due to diffusion, as was previously shown [15], and acts as a 


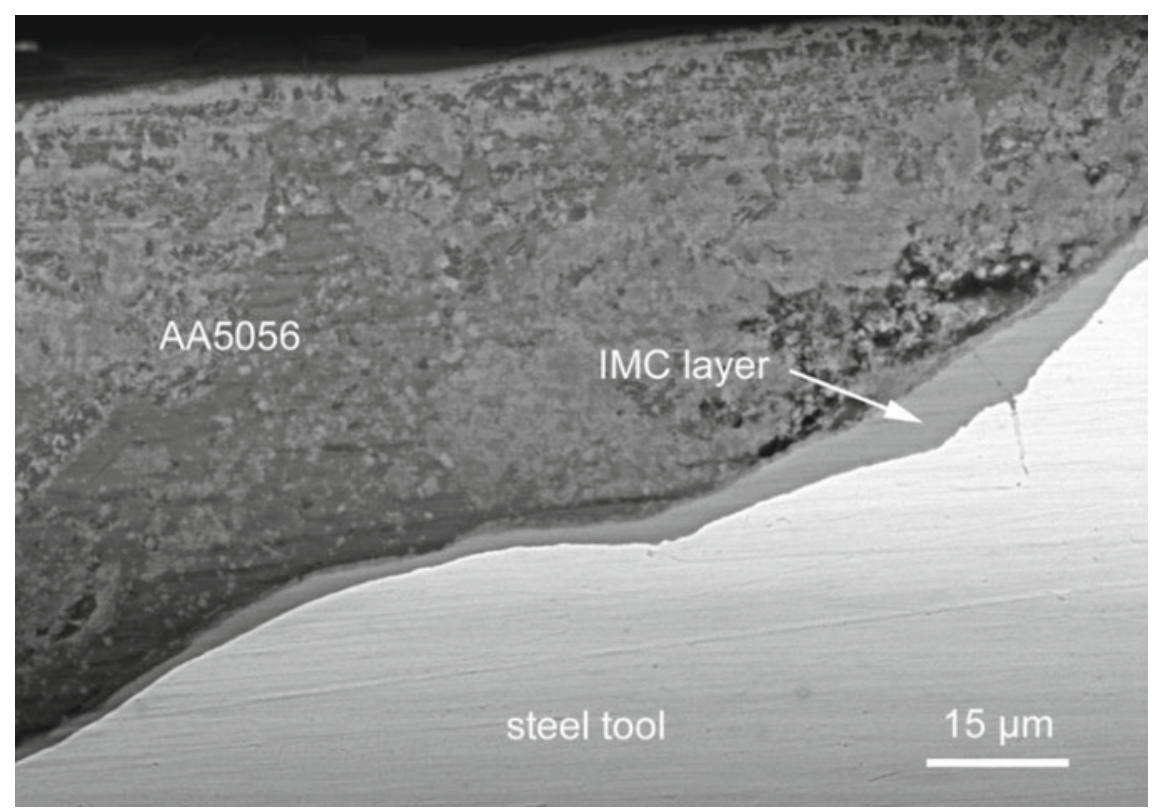

Fig. 5 Transfer layer and intermetallic compound on tool [15]

protector of the tool. In welding/processing of the aluminum alloy by the steel tool, a thin intermetallic Fe-Al layer up to $10 \mu \mathrm{m}$ in thickness is formed at the interface due to diffusion, which is harder than the tool material (Fig. 5). The intermetallic layer is coated by the processed material, with the transfer layer sticking to it due to cohesion forces. In overheating and durable operation of the tool, diffusion of the material into the tool increases, grain-boundary diffusion occurs in the form of specific intermetallide protrusions and the tool surface fractures. Thus, the adhesive-cohesive transfer in friction stir processing is a two-step process: formation of a natural protective coating on the tool and cohesive transfer of the material by this coating.

\section{Influence of Load on the Transfer Layer}

In the present work, we study the dependence of the transfer layer on the axial load. Since the relation of the tool feed and rotation rates to the layer thickness is indisputable, of particular interest is load, which is rarely studied, although it can affect the heat generation and friction coefficient. The study is performed on 2024 aluminum alloy sheets $8 \mathrm{~mm}$ in thickness. The material is milled to remove $0.5 \mathrm{~mm}$ of its clad surface and then processed by the friction stir tool with the $5 \mathrm{~mm}$ long pin. The pin length is chosen so as not to touch the platform if the tool would sink at high loads. The processing scheme is shown in Fig. 6. 


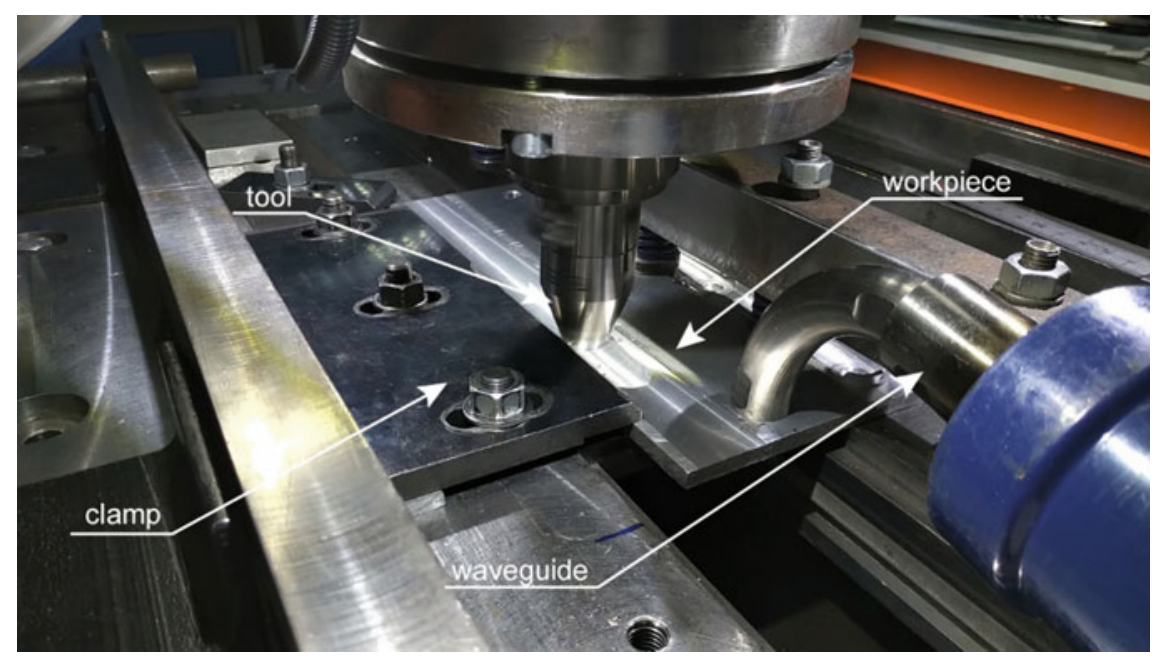

Fig. 6 Friction stir processing set up

Since the divergence of the measured transfer layer thickness from the previously calculated one is also observed at the acoustoplastic effect, friction stir processing is performed with ultrasonic assistance at the same parameters. Processing modes are given in Table 1. The ultrasonic power is $0.6 \mathrm{~kW}$. Ultrasound is transmitted into the sheet at the rigid fixation at the free end. The ultrasound generator works in an adaptive mode and provides a resonant input of vibrations without attenuation throughout the workpiece length. This method is described and investigated elsewhere [16].

Polished and etched longitudinal sections cut from the center of the processed material show a typical pattern of transfer layers (Fig. 6). Due to variation of the material etchability across the thickness, the layers are of different contrast. From the front surface to the root, the layers rotate in the direction of the processing pass. Since the tool plunge depth is less than the material thickness, a layer of untreated material is observed at the root surface, with a structure corresponding to the thermomechanically affected zone and the base material. At high loads, the untreated layer becomes narrower due to a deeper penetration of the tool shoulders.

The longitudinal section clearly demonstrates that rings on the front surface correspond to the etched transfer layers, i.e. they are of the same nature, despite the fact that they are formed by the shoulders on the front surface and by the pin in the bulk. Since transfer layers on the front surface are more pronounced, they are viewed in an Olympus LEXT-OLS4100 laser scanning microscope. 3D images of friction surfaces are used to construct 2D profiles of transfer layers (Fig. 7). From the profiles it is seen that the layers are asymmetric, often with two-high and low-peaks. Asymmetry of the peaks is apparently associated with material extrusion from under the tool shoulders in the opposite direction. However, where the layer starts and how the second peak is formed are nontrivial questions that require further research. Although peak asymmetry was observed earlier, for example, by Zuo et al. [17], the morphology 


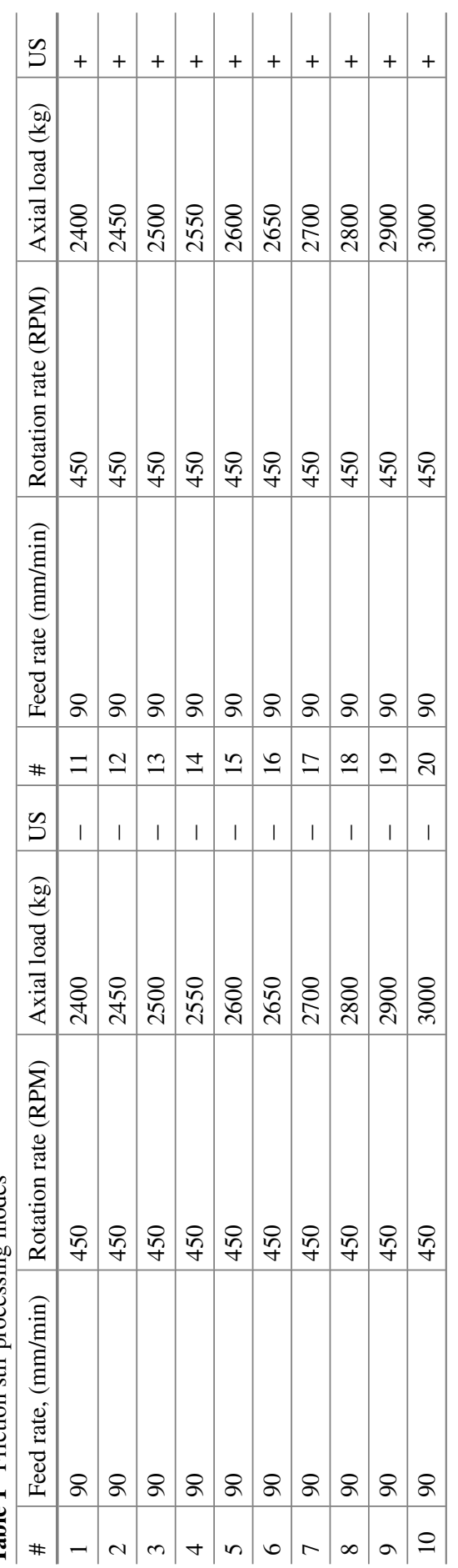


Fig. 7 Longitudinal sections of friction stir processed AA2024

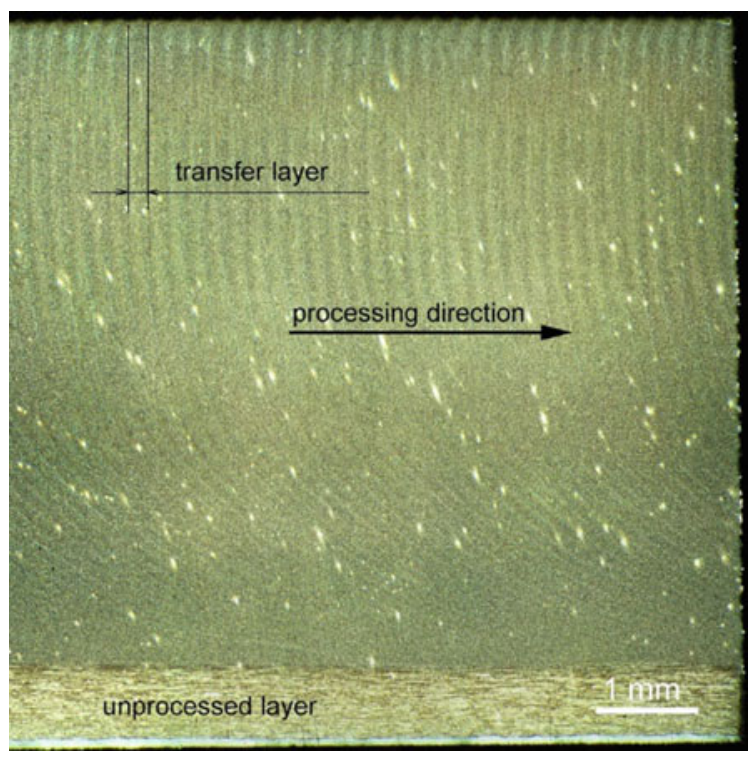

remains unexplained. Evidently, the transfer layer formation is a gradual process. A layer possibly starts at the beginning of the first peak, and ends at the subsequent valley. Assuming that a layer is formed per one revolution of the tool, the layer thickness will vary from 0 to $2 \pi\left(0^{\circ}-360^{\circ}\right)$. Thus, the shoulders gradually build up material layers with the peak formation, and the load causes them to rotate and extend. Each transfer layer actually consists of smaller layers of the material that is spread over the entire surface of the shoulders.

Pronounced peaks in the 2D profile allow an accurate construction of the load dependence of the transfer layer thickness. The measurement results are plotted in Fig. 8. The results show that the deviations of the transfer layer thickness are quite small and are within $6 \mu \mathrm{m}$. However, there is a clear dependence of these
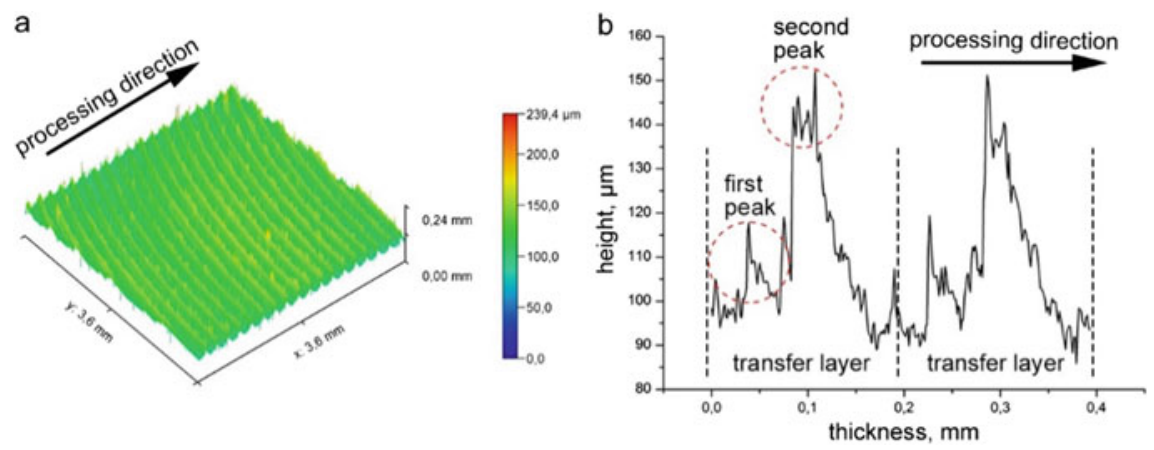

Fig. 8 Typical 3D images of the friction surface (a) and 2D profile of transfer layers (b) 
deviations on the load, which was previously predicted [10]. The diagram resembles a Gaussian or parabola, and its maximum values correspond to the feed to rotation rate ratio during processing at the load $2650-2700 \mathrm{~kg}$. The application of ultrasonic vibrations alters slightly the diagram, though the general pattern remains. The transfer layer thickness decreases slightly in this case (up to 3\%). A decrease in the transfer layer thickness with lower or higher load relative to the maximum is associated with insufficient adhesion/cohesion force during mass transfer. At insufficient load, the adhesive-cohesive bond is weaker, and, if the load is too high, the material overheats, working as a lubricant, which reduces the reverse transfer from the tool. In terms of technology and material quality, such a small change in the transfer layer thickness will probably be of little importance, but this allows a better understanding of the fundamental processes that occur during processing/welding.

The maximum thickness of the transfer layer is observed at the load $2700 \mathrm{~kg}$ with and without ultrasonic treatment, which is obviously associated with the material properties. During processing, the longitudinal force is measured along the tool path. Since aluminum alloys have high thermal conductivity, this force decreases during processing due to heating of the material in front of the tool. The longitudinal force is however independent of the load and ultrasonic vibrations and amounts to $409 \pm$ $35 \mathrm{~kg}$. By relating this value to the pin projection area, we derive the longitudinal welding stress, which is equal to $99 \mathrm{MPa}$. This stress corresponds to the yield point of 2024 alloy in compression at a temperature of $450{ }^{\circ} \mathrm{C}$ [18]. A close axial stress can be obtained at the load $3000 \mathrm{~kg}$ related to the projected pin area $(101 \mathrm{MPa})$. As mentioned above, at this load the tool shoulders become heated and sink into the workpiece. The axial stress at the load $2700 \mathrm{~kg}$ is $91 \mathrm{MPa}$, which is somewhat lower but still close. Thus, the largest mass transfer is observed in conditions close to the yield point of the material. A further increase in the load can lead to overheating of the material, a drop in its yield point and decrease in mass transfer.

During friction stir processing, the tool moment is also measured. The moment increases with load and ranges 15-21 Nm. Consequently, the friction force also increases. The experimentally measured moment is used to calculate the coefficient of friction of the pin by a formula similar to (2):

$$
\mu=\frac{M}{F_{z} \overline{R_{p}} \sin (\alpha / 2)}
$$

where $\overline{R_{p}}$ is the average pin radius $(4 \mathrm{~mm})$, and $\alpha$ is the pin cone angle $\left(30^{\circ}\right)$. Geometrically, the sine of the half-cone angle is equal to the cosine of the angle between axial force and support force.

The dependence of the calculated friction coefficient on the processing time shows (Fig. 9) that an increase in the load leads to an insignificant but stable decrease in the friction coefficient, despite a rise in the moment and friction force. This means that the moment and load growth is disproportional due to changes in the friction behavior. Ultrasound impact exerts no effect on the moment and friction coefficient at any load. 


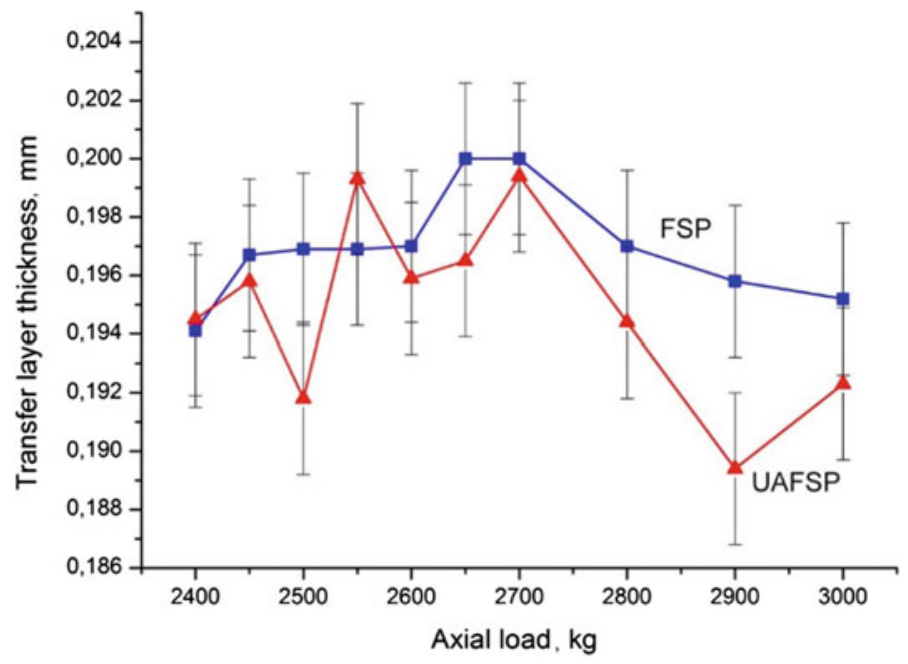

Fig. 9 The relationship between the transfer layer thickness and the axial load at friction stir processing and ultrasonic-assisted friction stir processing

This method of evaluating the friction coefficient or friction force is not quite adequate since the measured moment is a characteristic of the entire system. The evaluated value is an averaged one, but each tool region has its own moment, friction force, and friction coefficient on account of different sliding velocities at each radius. As is known, the friction coefficient depends on the speed not only in the case of viscous friction, but also during sliding. For example, in friction of a steel ball against lead or indium, the friction coefficient increases with speed, achieves a plateau, and falls again in the speed range $10^{-10}$ to $10 \mathrm{~cm} / \mathrm{s}$ [19]. Thus, the real friction coefficient at the average pin radius can differ strongly from the evaluated one. However, the above evaluation can be used to compare technological modes at the same radius (Fig. 10).

The process temperature is measured using a FLIR 655 SC thermal imaging camera. Thermal images are taken only of the material near the tool contour, which quickly cools, so the measured temperature will be less than the real one. However, the measurement results allow an estimation of the influence of the technological mode on the heat generation. The average process temperature, from the tool penetration to its removal, is used as a factor (Table 2). An increase in the load is expected to rise the average process temperature, which is associated with a more intense heat generation. An increase in the temperature during deformation additionally plasticizes the material, resulting in a decrease in the friction coefficient.

The application of ultrasonic vibrations, on the contrary, leads to a slight decrease in temperature, which is less obvious since the ultrasonic treatment itself causes heating of the material. During friction stir welding at the slip contact of the waveguide, the material is usually heated by $10-15{ }^{\circ} \mathrm{C}$ [20]. At the rigid fixation of the 

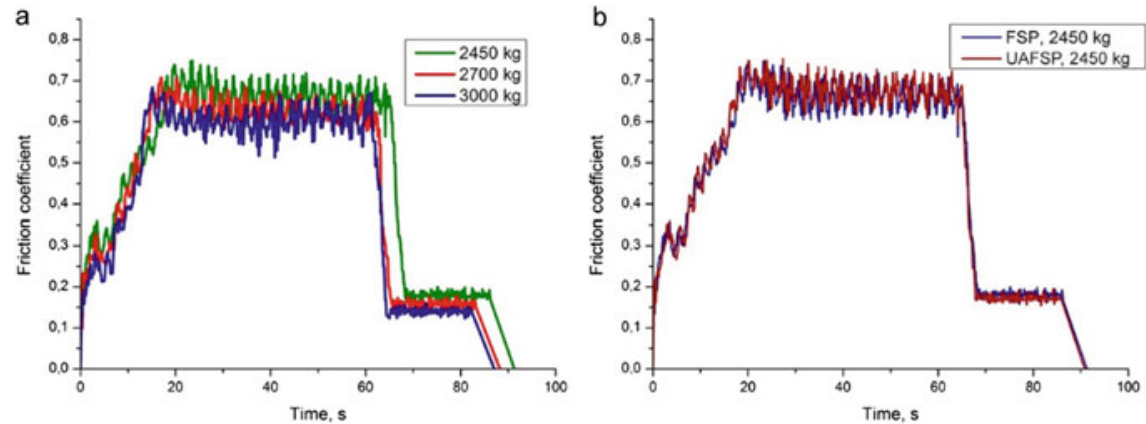

Fig. 10 The dependence of the calculated friction coefficient on the load (a); influence of ultrasonic impact on the calculated friction coefficient (b)

Table 2 The average friction stir processing temperature

\begin{tabular}{l|l|l|l}
\hline$\#$ & Load $(\mathrm{kg})$ & US & $\overline{\mathrm{t}}\left({ }^{\circ} \mathrm{C}\right)$ \\
\hline 2 & 2450 & - & 216 \\
\hline 12 & 2450 & + & 213 \\
\hline 7 & 2700 & - & 221 \\
\hline 17 & 2700 & + & 212 \\
\hline 10 & 3000 & - & 227 \\
\hline 20 & 3000 & + & 222
\end{tabular}

waveguide, the activation of the acoustoplastic effect apparently enhances the dissipation of thermal energy into the surrounding material. Nevertheless, this hardly affects the friction coefficient and the general moment.

Thus, the most effective mass transfer during friction stir processing occurs at loads that induce stresses close to the yield point of the material at the process temperature. Under these conditions, the transfer layer thickness is equal to the feed to rotation rate ratio. A reduction in the load decreases adhesion/cohesion and consequently mass transfer. An increase in the load also decreases mass transfer due to overheating of the material and reduces the friction coefficient. Intensification of deformation resulting from the acoustoplastic effect activated by ultrasound affects insignificantly the mass transfer characteristics.

\section{Surface Topography and Roughness}

The quality of structural components produced by friction stir welding/processing involves not only the strength characteristics of the material. An important criterion is also the surface quality of the components. The characteristic surface relief in the form of "onion rings", which is formed behind the advancing tool and is associated 
with the mass transfer process, can lead to undesirable consequences. The given part of the structure may be more prone to contamination, oxidation, corrosion, wear, etc. However, this issue has not yet been adequately addressed. The surface quality after welding/processing is evaluated only visually to identify macrodefects, such as shrinkage, tunnels, holes, oxidation, etc., because the fracture of an operating structure begins at these defects, if there are no other larger scale internal macrodefects [21]. Another defect is burr formation on both sides of the advancing tool, which reduces the cross-sectional area of the material in the stir zone. Burrs usually indicate that the welding/processing parameters were not properly selected, which leads, e.g., to overheating. However, the surface quality does not always imply a good quality of the joint in terms of strength. For example, as was shown in [22], an increase in the rotation rate during welding of AA5052 alloy led to a visually smoother surface, as well as to the formation of a tunnel defect. Thus, when selecting the optimal parameters, one should be guided by the quality criteria that are closest to the performance requirements.

The performance characteristics are affected not only by the presence of visible defects, but also by roughness. Visible defects on the surface are only a first approximation. With optimal parameters in terms of strength, these defects are usually absent, but the surface roughness is still pronounced. The roughness influences the fatigue characteristics and resistance to corrosion and wear [23]. In order to reduce the surface roughness, the process parameters can be further optimized within the range of previously selected optimal parameters or the surface can be post-processed. From a fundamental point of view, the surface topography and roughness can explain the mass transfer processes occurring in friction stir processing.

Within a certain range of process parameters, the roughness is significantly reduced with increasing rotation rate and decreasing feed rate, which is explained by a change in the transfer layer thickness according to Eq. (5). This was shown for 7075 aluminum alloy [17] and in dissimilar welding of A5052P-O aluminum and AZ31BO magnesium alloys [24]. In [17] it was shown that the topography of the front surface is self-similar, and its fractal dimension linearly correlates with the roughness. However, the given regularity is not observed for all materials. For example, for friction stir processed 7075 aluminum alloy/CBA, WFA, CSA PKSA or CFA matrix composites, the dependence of the roughness on the rotation rate is unstable, up to directly proportional one, i.e., the larger the rotation rate, the higher the roughness [25]. With somewhat higher or lower parameters, the roughness dependence is also nonlinear.

The search for optimal processing parameters in terms of roughness was made for 2017 aluminum alloy [26]. The authors clearly showed that the dependence of the roughness on process parameters is not always linear, even for homogeneous materials. In particular, an increase in the rotation rate at a low feed rate can lead to material overheating and numerous overlaps, which increases the roughness. The axial load, which has not been previously investigated in the given context, also has a nonlinear effect on the roughness. For example, with a rotation rate of $900 \mathrm{rpm}$ and a feed rate of $50 \mathrm{~mm} / \mathrm{min}$, an increase in the load from 500 to $1500 \mathrm{~N}$ led to an increase in the roughness, which obviously resulted from overheating due to large heat input. 
However, with other rotation rate and feed rate values, the roughness decreased with increasing load. These results indicate that various mechanisms are involved in the surface relief formation, and a linear dependence is observed only in special cases. In this regard, an important factor in addition to the process parameters is the thermal conductivity of the material and the amount of heat generated by friction.

Note that not all materials exhibit a well-defined morphology in the form of the onion ring structure. For example, this kind of structure was not observed in friction stir processed commercially pure titanium [27]. Judging by the relief topography, mass transfer on the surface was extremely unstable. The roughness was reduced with increasing load and the surface was generally smoothed, but unlike more ductile materials the surface demonstrated overlaps and tear.

In the present work, the surface roughness of friction stir processed 2024 aluminum alloy was examined using a laser scanning microscope Olympus LEXTOLS4100. The processing parameters are given in Table 1. Since the front surface is undulated and consists of rings (transfer layers), the roughness was analyzed for two cases: with and without subtracting the undulation (Fig. 11). In the case of subtracted undulation, the roughness is obviously lower, because it is measured with respect to a curved surface. In both cases, the load dependence of the roughness approximately resembles the load dependence of the transfer layer thickness with a maximum at $2700 \mathrm{~kg}$. In general, this is consistent with the results obtained in [26]. An increase in the axial load enhances the extrusion of the material behind the tool and hence the roughness increases, but above a threshold load value it decreases. As noted earlier, the yield point of the material is reached at a $3000 \mathrm{~kg}$ load, which may explain surface smoothing. Without subtracting the undulation, the roughness values changed drastically within the range of $7-21 \mu \mathrm{m}$. The roughness may also increase due to increasing plunge depth of the tool.

The application of ultrasonic vibrations destabilized the load-roughness dependence, which points to a less uniform dependence of the transfer layer thickness. This behavior is observed only when the undulation is subtracted. Without subtracting the undulation, the roughness increases with increasing load. The above behavior of the
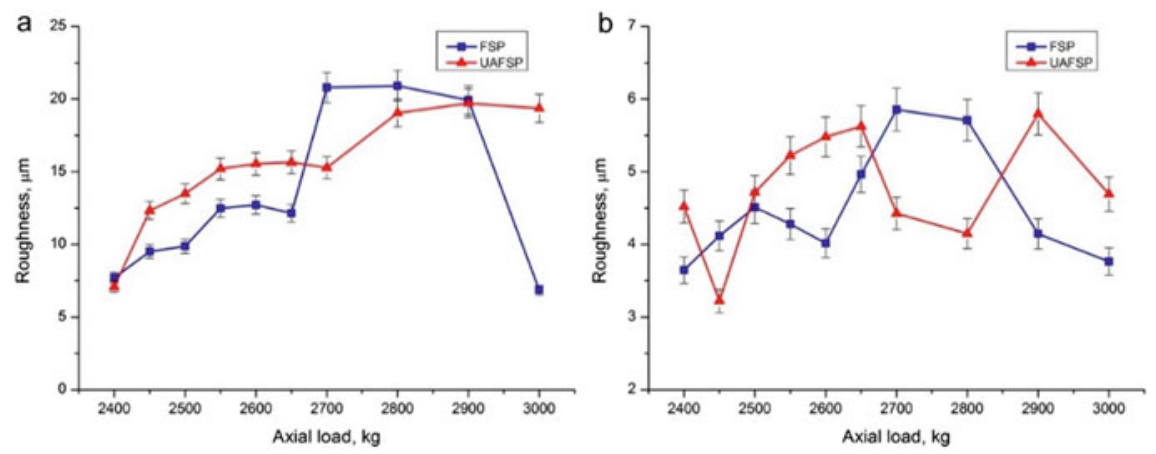

Fig. 11 Roughness of front surface without (a) and with subtracting the undulation (b) 
curve generally indicates that it is inappropriate to control the roughness through the load, because its maximum is achieved at an optimal load from the viewpoint of adhesive-cohesive mass transfer in friction stir processing. But it is precisely at this load that the surface roughness decreases as a result of ultrasound application. It is currently unclear whether the result is occasional or regular, but ultrasonic assistance can be considered as a way to reduce roughness.

At present, if necessary, the surface of the component in the stir zone is smoothed by mechanical post-processing, which is considered technologically inefficient in modern production. The use of more advanced post-processing techniques does not always provide the desired result. For example, as shown in [23], laser peening and shot peening did not significantly reduce the surface roughness of the joint. The friction characteristics of various samples differed slightly, although laser peening made the weld surface less stepped. Obviously, it is not always possible to achieve a good surface quality by varying the process parameters within the admissible parameter range; the quality often depends on the material. That is why the friction stir processing technology is being improved. The surface quality can be improved by using a stationary shoulder that allows for a smoother surface [28]. Drawbacks of this approach are that when the surface is smoothed immediately behind the tool it is not always possible to visually inspect surface defects.

\section{Conclusion}

The friction stir welding and processing technology has greatly evolved over almost 30 years of its development. Nevertheless, the fundamental explanation of the processes can be found in the works of 15 years ago. The then proposed scientific foundations in terms of thermomechanical processes generally well explain changes in the mechanical properties and microstructure, but they do not fully predict the behavior of materials. This is due to the nonlinear dynamics of the friction stir processes. In particular, deformation and heat generation are interdependent, which is often not taken into account in analytical solutions. Moreover, the material behaves differently at such large strains and strain rates in comparison with ordinary deformation. The melting temperature rises under high loading conditions, and other material properties, e.g., fluidity, change. Thus, the process dynamics implicitly depends on process parameters. These problems are approximately solved by modeling methods, without complete understanding of the friction stir processes as they are based on adhesive-cohesive mass transfer.

The complex mass transfer pattern is due to a combination of temperature, load, friction coefficient, material properties and sliding velocity, which are also largely interdependent. Here we showed that the load increase at a constant feed rate and tool rotation rate first causes an increase in the transfer layer thickness and then a decrease. This cannot be fully explained by the change in the coefficient of friction and temperature, because the average moment and temperature increase while the friction coefficient decreases. With increasing load, the adhesive-cohesive force between the 
tool and the surrounding material increases, resulting in larger material transfer. The maximum thickness of the transfer layer is observed at a stress close to the yield point of the material. A further increase in the load overheats the material and impairs mass transfer. The application of ultrasonic vibrations during friction stir processing, which causes the acoustoplastic effect and amplifies the deformation but does not increase the temperature and does not change the friction coefficient, leads to a decrease in the transfer layer thickness. This is evidently due to a change in the path length of the transferred material. Thus, the mass transfer in friction stir processing depends on the fundamental physical processes of bond and structure formation in the material at a fine level. The same effects influence the surface roughness of the processed material. In general, the load dependence of the roughness resembles that of the transfer layer thickness. An increase in the load enhances the extrusion of the transfer layer material from under the tool, but in overheating the shoulders smooth the surface. The roughness changes only slightly with ultrasound application, but it was found that at the optimal load in terms of the transfer layer thickness the ultrasonic treatment reduces the roughness.

These issues concerning friction stir processing/welding are rarely discussed as they are not of acute practical interest. However, their investigation can provide better fundamental understanding of mass transfer mechanisms. Presumably, the answers can be obtained from the studies of the transfer layer structure. Of particular interest is the asymmetry of the material asperities on the front surface as well as the different etchability of aluminum alloys over the layer thickness, which will be discussed in subsequent papers.

Acknowledgements The reported study was funded by RFBR and Tomsk Oblast according to Research Project No. 19-42-700002 (the results are reported in Sections 4-5) and performed within the frame of the Fundamental Research Program of the State Academies of Sciences for 2013-2020, line of research III.23.2.4 (the results in Sections 1-3).

\section{References}

1. Schmidt HNB, Hattel JH, Wert J (2004) An analytical model for the heat generation in friction stir welding. Modell Simul Mater Sci Eng 12(1):143-157

2. Mishra RS, De PS, Kumar N (2014) Friction stir welding and processing: science and engineering. Springer, Basel

3. Frigaard $\varnothing$, Grong $\varnothing$, Midling OT (2001) A process model for friction stir welding of age hardening aluminum alloys. Metall Mater Trans A 32(5):1189-1200

4. Colligan KJ, Mishra RS (2008) A conceptual model for the process variables related to heat generation in friction stir welding of aluminum. Scripta Mater 58:327-331

5. Kumar K, Kalyan C, Kailas SV, Srivatsan TS (2009) An investigation of friction during friction stir welding of metallic materials. Mater Manuf Process 24(4):438-445

6. Meyghani B, Awang MB, Poshteh RGM, Momeni M, Kakooei S, Hamdi Z (2019) The effect of friction coefficient in thermal analysis of friction stir welding (FSW). In: IOP Conference series: materials science and engineering, vol 495, Art. 012102. Science and engineering (CUTSE) international conference, 26-28 Nov 2018, Sarawak, Malaysia 
7. Long T, Tang W, Reynolds AP (2007) Process response parameter relationships in aluminium alloy friction stir welds. J Sci Technol Weld Joining 12(4):311-317

8. Schneider JA, Nunes AC Jr (2004) Characterization of plastic flow and resulting microtextures in a friction stir weld. Metall Mater Trans B 35(4):777-783

9. Liu XC, Wu CS (2015) Material flow in ultrasonic vibration enhanced friction stir welding. J Mater Process Technol 225:32-44

10. Eliseev AA, Kalashnikova TA, Gurianov DA, Rubtsov VE, Ivanov AN, Kolubaev EA (2019) Ultrasonic assisted second phase transformations under severe plastic deformation in friction stir welding of AA2024. Mater Commun 21:100660. https://doi.org/10.1016/j.mtcomm.2019. 100660

11. Wills JM, Harrison WA (1984) Further studies on interionic interactions in simple metals and transition metals. Phys Rev B 29:5486-5490

12. Panin VE, Surikova NS, Lider AM, Bordulev YuS, Ovechkin BB, Khayrullin RR, Vlasov IV (2018) Multiscale mechanism of fatigue fracture of Ti-6A1-4V titanium alloy within the mesomechanical space-time-energy approach. Phys Mesomech 21(5):452-463

13. Glezer M, Metlov LS (2010) Physics of megaplastic (severe) deformation in solids. Phys Solid State 52(6):1162-1169

14. Tarasov SY, Filippov AV, Kolubaev EA, Kalashnikova TA (2017) Adhesion transfer in sliding a steel ball against an aluminum alloy. Tribol Int 115:191-198. https://doi.org/10.1016/j.triboint. 2017.05.039

15. Tarasov SY, Kalashnikova TA, Kalashnikov KN, Rubtsov VE, Eliseev AA, Kolubaev EA (2015) Diffusion-controlled wear of steel friction stir welding tools used on aluminum alloys. AIP Conf Proc 1683:020228. https://doi.org/10.1063/1.4932918

16. Tarasov SY, Rubtsov VE, Fortuna SV, Eliseev AA, Chumaevsky AV, Kalashnikova TA, Kolubaev EA (2017) Ultrasonic-assisted aging in friction stir welding on Al-Cu-Li-Mg aluminum alloy. Weld World 61(4):679-690

17. Zuo L, Zuo D, Zhu Y, Wang H (2018) Effect of process parameters on surface topography of friction stir welding. Int J Adv Manuf Technol 98:1807-1816

18. Seidt JD, Gilat A (2013) Plastic deformation of 2024-T351 aluminum plate over a wide range of loading conditions. Int J Solids Struct 50:1781-1790. https://doi.org/10.1016/j.ijsolstr.2013. 02.006

19. Burwell JT, Rabinowicz E (1953) The nature of the coefficient of friction. J Appl Phys 24:136139. https://doi.org/10.1063/1.1721227

20. Shi L, Wu CS, Sun Z (2018) An integrated model for analysing the effects of ultrasonic vibration on tool torque and thermal processes in friction stir welding. Sci Technol Weld Joining 23(5):365-379. https://doi.org/10.1080/13621718.2017.1399545

21. Derazkola HA, Aval HJ, Elyasi M (2015) Analysis of process parameters effects on dissimilar friction stir welding of AA1100 and A441 AISI steel. Sci Technol Weld Joining 20(7):553-562. https://doi.org/10.1179/1362171815Y.0000000038

22. Moshwan R, Yusof F, Hassan MA, Rahmat SM (2015) Effect of tool rotational speed on force generation, microstructure and mechanical properties of friction stir welded $\mathrm{Al}-\mathrm{Mg}-\mathrm{Cr}-\mathrm{Mn}$ (AA 5052-O) alloy. Mater Des 66:118-128. https://doi.org/10.1016/j.matdes.2014.10.043

23. Hatamleh O, Smith J, Cohen D, Bradley R (2009) Surface roughness and friction coefficient in peened friction stir welded 2195 aluminum alloy. Appl Surf Sci 255(16):7414-7426. https:// doi.org/10.1016/j.apsusc.2009.04.011

24. Shigematsu I, Kwon YJ, Saito N (2009) Dissimilar friction stir welding for tailor-welded blanks of aluminum and magnesium alloys. Mater Trans 50(1):197-203. https://doi.org/10.2320/mat ertrans.MER2008326

25. Ikumapayi OM, Akinlabi ET (2019) Experimental data on surface roughness and force feedback analysis in friction stir processed AA7075 - T651 aluminium metal composites. Data Brief 23:103710

26. Langlade C, Roman A, Schlegel D, Gete E, Noel P, Folea M (2017) Influence of friction stir process parameters on surface quality of aluminum alloy A2017. In: MATEC web of conferences, vol 94, Art. 02006. https://doi.org/10.1051/matecconf/20179402006 
27. Eliseev AA, Amirov AI, Filippov AV (2019) Influence of axial force on the pure titanium surface relief during friction stir processing. AIP Conf Proc 2167(1):020077

28. Zhou Z, Yue Y, Ji S, Li Z, Zhang L (2017) Effect of rotating speed on joint morphology and lap shear properties of stationary shoulder friction stir lap welded 6061-T6 aluminum alloy. Int J Adv Manuf Technol 88:2135-2141

Open Access This chapter is licensed under the terms of the Creative Commons Attribution 4.0 International License (http://creativecommons.org/licenses/by/4.0/), which permits use, sharing, adaptation, distribution and reproduction in any medium or format, as long as you give appropriate credit to the original author(s) and the source, provide a link to the Creative Commons license and indicate if changes were made.

The images or other third party material in this chapter are included in the chapter's Creative Commons license, unless indicated otherwise in a credit line to the material. If material is not included in the chapter's Creative Commons license and your intended use is not permitted by statutory regulation or exceeds the permitted use, you will need to obtain permission directly from the copyright holder. 